\title{
Smart homes for the older population: particularly important during the COVID-19 outbreak
}

\author{
Karolina Gawrońska1 ID , Jacek Lorkowski ${ }^{2,3}$ ID \\ ${ }^{1}$ Rehabilitation Centre of the Central Clinical Hospital of the Ministry of the Internal Affairs and Administration in Warsaw, Poland \\ ${ }^{2}$ Clinical Department of Orthopaedics, Traumatology and Sports Medicine of the Central Clinical Hospital of the Ministry of the Internal \\ Affairs and Administration in Warsaw, Poland \\ ${ }^{3}$ Faculty of Health Sciences, Medical University of Mazovia, Warsaw, Poland
}

\begin{abstract}
Osteoporosis, one of the leading causes of disability in older adults, significantly reduces the quality of life and leads to loss of independence. Dynamic development of "smart" solutions based on artificial intelligence more and more commonly applied in older people's houses may be an answer to the above issues.

The aim of this study is to present selected "smart home" solutions for the diagnosis and prevention of falls in the older population through a literature review. The conducted meta-analysis based on a review of the scientific literature available in English and Polish in the Medline/PubMed, Embase, Scopus, and GBL databases was undertaken from 01.01.2015 to 01.10.2020 with the string search method using key words.

According to the authors of this study, the development of new technology based on artificial intelligence allows older people to live independently, which contributes to a higher level of life satisfaction and quality.
\end{abstract}

Key words: fall prevention, artificially intelligent home monitoring, innovative assisted living tools, home hazards.

\section{Introduction}

Osteoporosis is a metabolic disease characterized by a loss of bone density and changes in bone microarchitecture, which leads to significant reduction in the functional capacity and life quality of the older population [1]. This disease afflicts $22.1 \%$ of women and $6.1 \%$ of men over 50 years of age in the world. According to the data of the National Health Fund, the number of people suffering from osteoporosis in Poland, in 2018, was 2.1 million, including 1.7 million women [2].

The biomechanical parameters of bone tissue change with age, reducing its strength and contributing to fractures and poor global sagittal alignment as a result [1]. According to a study by Czerwinski et al. [3], the most common fractures are proximal femur fractures, including femoral neck and pertrochanteric fractures, distal forearm fractures, proximal humeral fractures, vertebral compression (mainly thoracic) frac- tures and lower rib fractures. In 2018, 120 thousand fractures reported in Poland were recognized as the effect of osteoporosis, including 34.7 thousand fractures of the proximal femur [2].

However, a growing number of studies focus on functional impairments such as spinal curvature deformity, poor sagittal balance and decreased trunk mobility. Postural changes in the spine, especially thoracic hyperkyphosis, commonly known as dowager's hump or lumbar kyphosis, lead to an increased deflection of the body's centre of gravity which in combination with a limited visual field caused by poor global sagittal alignment additionally contributes to falls [4].

After the outbreak of the SARS-CoV-2 epidemic, with the introduction of lockdown and the consequent decrease in the number of high-energy injuries resulting from traffic accidents and sports injuries, the problem of low-energy fractures caused by slips, trips and falls at home came to the foreground. 
A study by Zhu et al. [5] in China showed that hip fractures were among the most frequent (58.3\% of all fractures). The dominant mechanism of injury was a fall from a standing position, representing a proportion of $89.4 \%(405 / 453)$. It has been found that $72.7 \%$ of all fractures occurred in the patient's home [5].

The study by Lv et al. [6] revealed that he proportion of osteoporotic fracture - $32.5 \%$ - in the epidemic group was significantly higher than that of the control group (before the COVID-19 epidemic) - 26.9\%. Among osteoporotic fractures in the epidemic group, hip fractures accounted for $68.4 \%$ of all fractures, then thoracolumbar vertebra fracture (17\%), proximal humerus fracture (9.9\%), and distal radius fracture (4.8\%). In the control group, hip fractures accounting for $57.8 \%$ of osteoporotic fractures, followed by thoracolumbar vertebra fracture $(24.3 \%)$, distal radius fracture $(11.5 \%)$ and proximal humerus fracture (6.4\%) [6].

Statistically, one in three people in the world over 65 years of age falls every year, and half of them fall at least twice [7]. According to the WHO, determining the real cause of falls in older people is difficult due to the coexistence of many potential causes of falls [8].

The analysis of publications among the most important factors indicates the issues related to posture and balance control of various aetiologies, sarcopenia, gait disturbances caused by various conditions and weakness syndrome [9-11]. It has also been shown that a positive history of falls in the past and fear of falling contribute to its occurrence $[12,13]$. An increased risk of falling is caused by visual impairment including visual field impairment and visual quality [14, 15], dizziness, changes in orthostatic pressure and arrhythmias [16, 17]. Behavioural factors such as limited physical activity, use of inappropriate footwear, polypharmacy, and taking certain medications also increase the risk of falls [11, 18-22].

The study shows that environmental risk factors related to the design and arrangement of space are perceived by older people as direct causes of falls [23]. It has been proved that slippery floors, the absence of anti-slip mats, handles and handrails for showers and restrooms, uneven surfaces, carpets and rugs, inadequate lighting, cables on the floor, as well as unadjusted height of furniture and sanitary facilities, contribute to falls [24-27]. Therefore, in order to meet the real needs of seniors, the accommodation spaces should be designed and adapted in accordance with the concept of the "smart home", using new technology solutions that increase the convenience and comfort of use, and above all the safety, of seniors.

The aim of the study is to present selected "smart home" solutions for the diagnosis and prevention of falls in the older population, particularly with osteoporosis, based on a literature review.

\section{Material and methods}

An analysis of the English scientific literature available in the MEDLINE/PubMed, Embase, and Scopus databases was undertaken from 2015 to 2020 to identify relevant articles on smart home technology for accidental falls with the string search method. Additionally, a manual search (hand searching) of the Polish publications available in GBL and the Google Scholar search engine was carried out.

The adopted methodology of article selection was based on the designed scheme of searching for scientific reports using key words as shown in the figure below (Figure 1). A variety of synonymous terms were

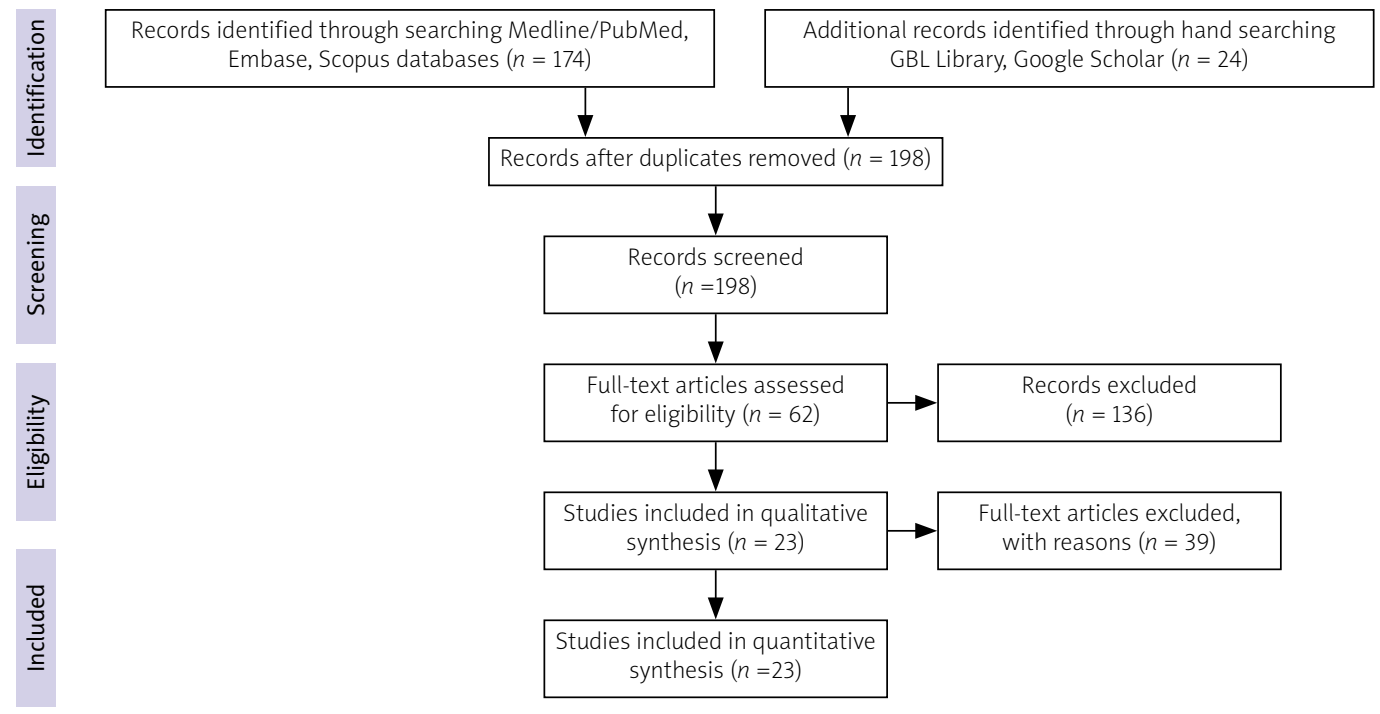

Fig. 1. Scheme of the selection of analysed articles. 
Table I. Key words and synonyms

\begin{tabular}{|lr|}
\hline Key word & \multicolumn{1}{c|}{ Synonyms } \\
\hline Smart Home & Assistive technology (MeSH), Self-help devices (MeSH), Artificial intelligence (MeSH) in eldercare \\
\hline Elderly & Aged (MeSH), Aging (MeSH), Older adults \\
\hline Home Accidents (MeSH) & Accidental falls (MeSH), Fall and slip (MeSH) \\
\hline
\end{tabular}

MeSH - Medical Subject Headings.

combined using Boolean logic, and a collection of three groups of key words was selected: 1) smart home, 2) elderly, 3) home accidents. To include all relevant publications, their thesaurus equivalent words and associated Medical Subject Headings Terms, i.e. assistive technology, smart home technology, self-help devices, artificial intelligence (AI), elderly, aging, aged, older adults, home accidents, accidental falls and fall and slip in older population were also used in the search (Table I).

The article is based on quantitative, qualitative, mixed method peer-reviewed publications, and published conference papers.

Inclusion criteria:

- published between 01.01.2015 and 25.09.2020 in English or Polish,

- peer-reviewed journal articles and published conference papers,

- studies focused on novel self-help devices, artificial intelligence, and smart technology helping to maintain independence of older adults,

- publications focus on the prevention of accidental falls and slips,

- aged 65 and older.

Exclusion criteria:

- published before 01.01.2015 and in languages other than English and Polish,

- article type: books and documents.

The works obtained included: clinical trial, randomized controlled trial, meta-analysis, systematic reviews case reports, conference papers.

\section{Results}

As a result of the algorithm search, a total of 198 works were found. After excluding duplicates and articles that were not quite thematically relevant for verification, based on titles and abstracts, 62 results were obtained. After careful examinations of the content of 62 articles, 23 of them were recognized by the authors as the most important and innovative information and those are subsequently discussed in this study.

Based on a full-text analysis of 62 articles, the obtained results have been organized into the following categories (Table II).
Table II. Highlighted categories based on the "Smart Home" key words with synonyms in the analysed literature

\begin{tabular}{|l|}
\hline 1. Fall detection system [29-36] \\
\hline 2. Smart home appliances control [37, 38] \\
\hline 3. Assistive devices [39-41] \\
\hline 4. eHealth [42, 43] \\
\hline $\begin{array}{l}\text { 5. Design and equipment of accommodation spaces } \\
\text { customised to the needs of older people [25, 27-46] }\end{array}$ \\
\hline
\end{tabular}

The first category contains articles on both the detection and prediction of falls based on gait analysis, real-time monitoring of people, and data analysis from wearable and environmental sensors. The issues related to this topic are presented in 34 articles. Another category distinguished by the authors encompasses all innovative solutions for controlling home appliances and home equipment to increase the safety and comfort of use by older adults. This fact is pointed out by the authors of 5 analysed publications. The issues related to the use of assistive devices by older people, such as walkers, canes, crutches, as well as robotic assistants, are discussed in 5 reviewed articles. Remote health monitoring and the development of telemedicine services are the main topics of 7 articles found.

In this article, due to the existing differences in searching by key words in English and Polish, it was necessary to refrain from thoroughly discussing the topic of designing and furnishing accommodation spaces that meet the needs of the older population. This issue, in the opinion of the authors with a rich, well-developed bibliography, exists under the term MeSH: Housing for the Elderly and is not a subject of this analysis. For this reason, the authors selected only 11 articles, including English articles devoted mainly to assistive devices in the bathroom and restroom that ensure safety during the transfers.

The collection of articles presented below is subjective; it indicates which innovations - in the authors' opinion - are effective. According to the authors of this publication, the discussed issues concerning "smart home" solutions for the diagnosis and prevention of falls in the older population provide a new approach to 
the practical methods of using innovations, arising from the development of artificial intelligence techniques, in everyday life.

\section{Discussion}

Accommodation spaces customized to the needs of older people using the "smart" concept minimize the necessity for another person's interference, supporting seniors' sense of independence and self-sufficiency in their own environment. Adaptation of accommodation spaces should be compliant with the safety rules, convenient to use and easy to maintain [28].

In the literature examined, attention is drawn to the wide application of new technology to predict and identify falls. It shows that machine learning algorithms and a predictive approach are perfectly suited to the fall detection systems $[29,30]$. The algorithms rely on individualized wearable sensors, ambient sensors, e.g. using a 3D camera system or mixed sensors [31, 32]. Small sensors, which are usually placed with a strap or glued to the tested person's body, can also be correlated with phones, smart watches or special clothing. After collecting motion readings from the sensors in real time, the data are transferred to the application via a wireless network to provide a 3D model [33]. The most common sensors include inclinometers, vertical gyroscopes, vertical reference units, inertial measurement units, position and course information systems, and INS/GPS based navigation systems [34, 35]. A study by de Miguel et al. [36] points to the fact that the disadvantage of using fall detectors based on wearable sensors is a high probability that the older people may forget to put on the sensors.

The development of new technology used in the prediction and detection systems based on machine learning algorithms and the predictive approach may help to prevent falls and their consequences; however, further investigations are needed.

Analysing the literature in the category of smart home appliance control, it is possible to name: intelligent motion sensor-based lightning, automatic window blinds, room temperature control, receiving alerts, e.g. from smoke detectors, power on and off detectors, and meters transmitting data via radio. Particular attention should be paid to strong and uniform lighting of floors, stairs and worktops. Spot lighting for suspended ceilings and skirting boards with LED lighting are recommended. Lighting in the room should imitate daylight following the circadian rhythm, i.e. to maintain consistent light and colour levels, affecting the endocrine system [37, 38]. Smart control of home appliance and equipment increases seniors' sense of security and comfort of use.

The innovative assistive devices include assistive robots and assistive equipment, e.g. a cane or a walker, which are additionally equipped with an automatic system projecting laser visual guidance [39, 40].

Pfripl et al. [39] conducted a study called the "HOBBIT Project" on the impact of social robots on seniors' selfreliance and sense of independence. The purpose of the project was to put inexpensive robots into domestic use and thereby reduce the risk of falls and assure support in emergencies. The results confirmed the intuitive operation of the robot and its functionality corresponding to the needs of the seniors, while the respondents perceived the robot more as a toy than a device supporting independent living. Moreover, the authors proved that despite the emergency function of the robot in life-threatening situations, the sense of safety did not increase [39].

Another innovative assistive tool used by older people additionally diagnosed with Parkinson's disease is a system designed to detect the so-called freezing of gait (FOG) and falls, as well as to monitor and improve mobility with laser visual guidance projected by an automatic laser system. The tool relies on an automatic, unobtrusive and dynamic visual guidance system based on laser line projection. The RGB-D sensors use Microsoft Kinect $\mathrm{V} 2$ and a laser projection system. A study by Amini et al. [41] indicates absolute usefulness of the device in terms of increasing mobility and improving gait. In the study group, $86.6 \%$ of people were satisfied with the system's detection of FOG incidents. On the other hand, the authors also draw attention to the existing drawbacks of the system, such as coverage in rooms and the necessity to install the system in different areas of the house that are used most often [41]. The laser projection system functionality also applies to the assistive equipment a walker. The laser projecting a line on the floor is activated by pressing an additional button in the walker handle. The purpose of such a solution is to improve gait, and promote everyday activity, both inside and outside the accommodation space [40].

The application of innovative solutions to assistive devices, such as a walker, significantly improves the gait quality. Putting assistive robots into practical use may face restrictions on the part of the older people, who may refuse to use them or treat them as toys, preventing them from fulfilling their intended function.

In the eHealth category, there are various health monitoring systems based on wearable sensors too and on the integration of several tools with environmental sensors, platforms for monitoring the biological signals of tested subjects as well as a data transmission system. Health monitoring includes electrocardiography, respiratory rate, heart rate, body temperature, and falls. The system integration enables real-time health monitoring as well as sending alerts in life-threating cases. The continuous development of e-Health services 
creates possibilities for older people to maintain maximum independence, which translates into an increase in satisfaction and quality of life [42, 43].

Numerous scientific reports indicate that trunk deformities also lead to chronic back pain, worsen the quality of gait and significantly reduce physical activity, e.g. climbing stairs. Taking into account the above health restrictions, potential facilities in the accommodation spaces aim to create safe conditions and enable independent lifestyle. Locomotion safety is ensured by an adequate amount of space for movement, elimination of obstacles (thresholds, carpet edges, wires and other items that may cause accidental falls), appropriate anti-slip surface, the possibility of using additional equipment such as handrails and handles, optimal room lighting and application of the principle of colour contrast to the elements of home furnishings [25, 27, 28, 38]. The authors recommend such a layout of the rooms and arrangement of the property that enables optimal movement along the communication routes, without the necessity to cover long distances [38].

According to Wilson et al. [44], everyday appliances and frequently used elements of equipment such as light switches, handles, electrical sockets, cabinets, shelves, and drawers should be installed at a height that does not require bending and within reach of the arms of a person in a wheelchair. In the literature, special attention is paid to restroom handles for toilet transfers. The authors agree that with the double vertical handles the transfers are significantly more effective and best controlled in senior facilities [45-47]. Through the adaptation of the accommodation spaces to the functional abilities of people living in them, worsening with age, older people can enjoy self-sufficiency and independence for a longer time.

Adapting the rooms to ensure seniors' safety is also beneficial from an economic point of view. In 2018, the value of reimbursement of benefits in Poland due to osteoporotic fractures amounted to PLN 476 million [2]. From this point of view, the interior design as well as appropriate finishing and equipment, i.e. adapted manoeuvring zones for a wheelchair, items facilitating the sense of direction, selection of finishing and furnishing materials that are easy to clean and maintain, reduction of objects, and organized storage space, can indirectly contribute to reduction of the incidence of osteoporotic fractures $[43,44]$.

\section{Conclusions}

Preventing home hazards that cause low-energy injuries to the elderly population should become a priority in comprehensive geriatric care. The development of new technology based on "smart home" innovative solutions allows older people to be independent, contributing to a higher level of satisfaction and quality of life; however, since not all solutions are approved by seniors, further investigations are needed.

The authors declare no conflict of interest.

\section{References}

1. Gunay Ucurum S, Altas EU, Ozer Kaya D. Comparison of the spinal characteristics, postural stability and quality of life in women with and without osteoporosis. J Orthop Sci 2020: 25: P960-965, DOI: 10.1016/j.jos.2019.12.015.

2. Raport „NFZ o zdrowiu. Osteoporoza”. Warszawa 2019. Retrieved on 05.10 .2020 on: https://zdrowedane.nfz.gov.pl/ pluginfile.php/211/mod_resource/content/6/1911_nfz_o_ zdrowiu_osteoporoza.pdf.

3. Czerwiński E, Czubak J, Synder M, et al. Contemporary Management of Osteoporotic Fractures. Ortop Traumatol Rehabil 2018; 20: 91-102, DOI: 10.5604/01.3001.0011.7665

4. Mohebi S, Torkaman G, Bahrami F, Darbani M. Postural instability and position of the center of pressure into the base of support in postmenopausal osteoporotic and nonosteoporotic women with and without hyperkyphosis. Arch Osteoporos 2019; 14: 58, DOI: 10.1007/s11657-019-0581-6.

5. Zhu Y, Chen W, Xin X, et al. Epidemiologic characteristics of traumatic fractures in elderly patients during the outbreak of coronavirus disease 2019 in China. Int Orthop 2020; 44: 1565-1570, DOI: 10.1007/s00264-020-04575-0.

6. Lv H, Zhang Q, Yin Y, et al. Epidemiologic characteristics of traumatic fractures during the outbreak of coronavirus disease 2019 (COVID-19) in China: A retrospective \& comparative multi-center study. Injury 2020; 51: 1698-1704, DOI: 10.1016/ j.injury.2020.06.022.

7. Patel D, Ackermann RJ. Issues in Geriatric Care: Falls. Fp Essentials 2018; 468: 18-25.

8. Global Report on Falls Prevention in Older Age. Organization GWH 2007; https://extranet.who.int/agefriendlyworld/ wp-content/uploads/2014/06/WHo-Global-report-on-fallsprevention-in-older-age.pdf [Accessed 2020.03.18].

9. Amarowicz J, Czerwiński E, Zając K, Kumorek A. Fracture Liaison Services - Polish Experience. Methods of Secondary Prevention of Osteoporotic Fractures. Ortop Traumatol Rehabil 2016; 18: 569-581, DOI: 10.5604/15093492.1230554.

10. Kusz-Rynkun A, Żarnowska I. Sarcopenia and osteoporosis cofactors of increased risk of falls and bone fractures. Post N Med 2017; 30: 11-15.

11. Gawronska K, Lorkowski J. Upadki i starzenie się, a zdrowie publiczne - przegląd piśmiennictwa. Ortop Traumatol Rehabil 2021 [in press].

12. Prabhakaran K, Gogna S, Pee S, et al. Falling Again? Falls in Geriatric Adults-Risk Factors and Outcomes Associated With Recidivism. J Surg Res 2020; 247: P66-76, DOI: 10.1016/j.jss. 2019.10.041.

13. Chiu AS, Jean RA, Fleming M, Pei KY. Recurrent Falls Among Elderly Patients and the Impact of Anticoagulation Therapy. World J Surg 2018; 42: 3932-3938, DOI: 10.1007/s00268-018-4728-1.

14. Niihata K, Fukuma S, Hiratsuka Y, et al. Association between vision-specific quality of life and falls in community-dwelling 
older adults: LOHAS. PLoS One 2018;13: e0195806, DOI: 10.1371/ journal.pone.0195806.

15. Leat SJ, Zecevic AA, Keeling A, et al. Prevalence of vision loss among hospital in-patients; a risk factor for falls? Ophthalmic Physiol Opt 2018; 38: 106-114, DOI: 10.1111/opo.12428.

16. Jahn K. The Aging Vestibular System: Dizziness and Imbalance in the Elderly. Adv Otorhinolaryngol 2019; 82: 143-149, DOI: $10.1159 / 000490283$.

17. Dalgaard F, Pallisgaard JL, Numé AK, et al. Rate or Rhythm Control in Older Atrial Fibrillation Patients: Risk of Fall-Related Injuries and Syncope. J Am Geriatr Soc 2019; 67: 2023-2030, DOI: 10.1111/jgs.16062.

18. Wołoszyn N, Wiśniowska-Szurlej A, Sozański B. An assessment of the relationship between the level of physical activity and the risk of falls and depression in elderly adults aged 60-75 years from the Podkarpackie region. Post Rehabil 2018 32: 41-48, DOI: 10.5114/areh.2018.77936.

19. Lorkowski J, Mrzygłód M, Kotela I, et al. Obuwie zgodne z „business dress code” a kondycja zdrowotna stóp kobiet komputerowo wspomagana ocena holistyczna. Ann Acad Med Stetin 2013; 59: 118-128.

20. Bartoszek A, Sagan A, Korga W, Szalast K. Falls among elderly and their connection with polypharmacy and polypragmasy. J Educ Health Sport 2018; 8: 667-673.

21. Haasum $Y$, Johnell K. Use of antiepileptic drugs and risk of falls in old age: A systematic review. Epilepsy Res 2017; 138 98-104, DOI: 10.1016/j.eplepsyres.2017.10.022.

22. Tan MP, Tan GJ, Mat S, et al. Use of Medications with Anticholinergic Properties and the Long-Term Risk of Hospitalization for Falls and Fractures in the EPIC-Norfolk Longitudinal Cohort Study. Drugs Aging 2020; 37: 105-114, DOI:10.1007/s40266019-00731-3.

23. Cockayne S, Pighills A, Adamson J, et al. Can occupational therapist-led home environmental assessment prevent falls in older people? A modified cohort randomised controlled tria protocol. BMJ Open 2018; 8: e022488, DOI: 10.1136/bmjopen2018-022488.

24. Bartoszek A, Kocka K, Bartoszek A, et al. Wybrane czynniki ryzyka upadków wśród osób starszych mieszkających w środowisku wiejskim. J Educ Health Sport 2016; 6: 625-636, DOI 10.5281/zenodo.61044.

25. Blanchet R, Edwards N. A need to improve the assessment of environmental hazards for falls on stairs and in bathrooms: results of a scoping review. BMC Geriatr 2018; 18: 272, DOI: 10.1186/s12877-018-0958-1.

26. Park J, Lee K, Lee K. Association between urinary urgency and falls among rural dwelling older women. J Adv Nurs 2020; 76 846-855, DOI: 10.1111/jan.14284.

27. Cuevas-Trisan R. Balance Problems and Fall Risk in the Elderly. Phys Med Rehabil Clin N Am 2017; 28: 727-737, DOI: 10.1016/ j.pmr.2017.06.006

28. de Baat C, de Baat P, Gerritsen AE, et al. Risks, consequences, and prevention of falls of older people in oral healthcare centers. Spec Care Dentist 2017; 37: 71-77, DOI: 10.1111/scd.12212.

29. Riquelme F, Espinoza C, Rodenas T, et al. eHomeSeniors Dataset: An Infrared Thermal Sensor Dataset for Automatic Fall Detection Research. Sensors (Basel) 2019; 19: 4565, DOI: 10.3390/s19204565.

30. Porter AS, Harman S, Lakin JR. Power and perils of prediction in palliative care. Lancet 2020; 395: 680-681, DOI: 10.1016/ S0140-6736(20)30318-4.
31. Tsinganos P, Skodras A. On the Comparison of Wearable Sensor Data Fusion to a Single Sensor Machine Learning Technique in Fall Detection. Sensors (Basel) 2018; 18: 592, DOI: 10.3390/s18020592.

32. Xiong GL, Bayen E, Nickels S, et al. Real-time video detection of falls in dementia care facility and reduced emergency care. Am J Manag Care 2019; 25: 314-315.

33. Walsh L, Doyle J, Smith E, et al. Continuous real-world gait monitoring in community-based older adults. Annu Int Conf IEEE Eng Med Biol Soc 2015; 2015: 3719-3722, DOI: 10.1109/ EMBC.2015.7319201.

34. Collier S, Monette P, Hobbs K, et al. Mapping Movement: Applying Motion Measurement Technologies to the Psychiatric Care of Older Adults. Curr Psychiatry Rep 2018; 20: 64, DOI: 10.1007/s11920-018-0921-z.

35. Sun R, Sosnoff JJ. Novel sensing technology in fall risk assessment in older adults: a systematic review. BMC Geriatr 2018; 18: 14, DOI: 10.1186/s12877-018-0706-6.

36. de Miguel K, Brunete A, Hernando M, Gambao E. Home CameraBased Fall Detection System for the Elderly. Sensors (Basel) 2017; 17: 2864, DOI: 10.3390/s17122864.

37. Bailey C, Aitken D, Wilson G, et al. "What? That's for Old People, that." Home Adaptations, Ageing and Stigmatisation: A Qualitative Inquiry. Int J Environ Res Public Health 2019; 16 : 4989, DOI: 10.3390/ijerph16244989.

38. Materiały konferencyjne: Architektura i przestrzeń przyjazna seniorom. Narodowy Instytut Zdrowia Publicznego - Państwowy Zakład Higieny, Warszawa 27.11.2018.

39. Pripfl J, Körtner T, Batko-Klein D, et al. Social service robots to support independent living : Experiences from a field trial. Z Gerontol Geriatr 2016; 49: 282-287, DOI: 10.1007/s00391016-1067-4

40. Luz C, Bush T, Shen X. Do Canes or Walkers Make Any Difference? Non Use and Fall Injuries. Gerontologist 2017; 57 : 211-218, DOI: 10.1093/geront/gnv096.

41. Amini A, Banitsas K, Young WR. Kinect4FOG: monitoring and improving mobility in people with Parkinson's using a novel system incorporating the Microsoft Kinect v2. Disabil Rehabil Assist Technol 2019; 14: 566-573, DOI: 10.1080/17483107. 2018.1467975.

42. Costa SE, Rodrigues JJ, Silva BM, et al. Integration of Wearable Solutions in AAL Environments with Mobility Support. J Med Syst 2015; 39: 184, DOI: 10.1007/s10916-015-0342-z.

43. Tutak JS, K. Urządzenie do bezprzewodowej diagnostyki stanu zdrowia osoby starszej. Acta Bio-Optica Inf Med Inż Biomed 2016; 22: 37-43.

44. Wilson G, Aitken D, Hodgson P, Bailey C. The hidden impact of home adaptations: Using a wearable camera to explore lived experiences and taken-for-granted behaviours. Health Soc Care Community 2019; 27: 1469-1480, DOI: 10.1111/hsc.12818.

45. Lee SJ, Sanford J, Calkins M, et al. Beyond ADA Accessibility Requirements: Meeting Seniors' Needs for Toilet Transfers. HERD 2018; 11: 32-44, DOI: 10.1177/1937586717730338.

46. King EC, Novak AC. Effect of Bathroom Aids and Age on Balance Control During Bathing Transfers. Am J Occup Ther 2017; 71: 7106165030p1-7106165030p9, DOI: 10.5014/ajot.2017.027136.

47. Kennedy MJ, Arcelus A, Guitard P, et al. Toilet Grab-Bar Preference and Center of Pressure Deviation During Toilet Transfers in Healthy Seniors, Seniors With Hip Replacements, and Seniors Having Suffered a Stroke. Assist Technol 2015; 27: 78-87, DOI: 10.1080/10400435.2014.976799. 